\title{
EL ALCÁZAR DE MADRID. DEL CASTILLO TRASTÁMARA AL PALACIO DE LOS AUSTRIAS (Ss. XV-1543)
}

\author{
Begoña Alonso Ruiz \\ Universidad de Cantabria
}

\begin{abstract}
El alcázar medieval de Madrid se convirtió en la gran residencia de los Austrias desde la llegada de Carlos I al reinado de Carlos II. En la Nochebuena de 1734, reinando ya Felipe V de Borbón, el palacio sufrió un devastador incendio, resultado del cual se inicia la construcción del nuevo Palacio Real, ya barroco, sobre su solar. En esta investigación nos ocupamos de reconstruir la historia -hasta ahora fragmentada- de ese castillo medieval, aportando nuevos datos documentales acerca de las sucesivas intervenciones sufridas en el edificio. Nos centramos de forma especial en las obras realizadas en el período de los Reyes Católicos $\mathrm{y}$ en las primeras encargadas por Carlos V, antes de la definitiva real cédula de 1536 que marca el comienzo de un nuevo capítulo en la historia constructiva del edificio al transformarse de manera definitiva el viejo castillo en un palacio residencial, pero subrayando al tiempo el valor simbólico de la "Cuadra Rica" y las salas de aparato de la época Trastámara.
\end{abstract}

Palabras clave: Arquitectura tardogótica; Obras reales; Reales alcázares; Juan II; Enrique IV; Reyes Católicos; Carlos V; Alonso de Covarrubias.

\section{THE MADRID ALCÁZAR. FROM TRASTÁMARA CASTLE TO PALACE OF THE AUSTRIAS (15TH CENTURY-1543)}

The medieval Alcázar (fortress) of Madrid was transformed into the residential palace of the Austrian dynasty in Spain from the reign of Charles I through that of Charles II. On Christmas Eve 1734, during the reign of the Bourbon king Philip V, the palace suffered a devastating fire, resulting in the construction of a new Royal palace, already baroque, on the same site. This research reconstructs the history - until now fragmented - of this lost medieval castle, contributing new source materials concerning the successive interventions carried out on the building. Specifically, this investigation focuses on the improvements realized during the period of the Catholic Monarchs and the first works commissioned by Charles V, prior to the definitive royal bond of 1536 . This document marks the beginning of a new chapter in the constructive history of the building, when the old castle was transformed definitively into a residential palace, while highlighting the symbolic value of the Sala Rica and the rooms of protocol constructed during the Trastámara period.

Key words: Late Gothic architecture; Royal works; Royal fortresses; John II; Henry IV; Catholic Monarchs; Charles V; Alonso de Covarrubias. 


\section{El alcázar medieval}

La primera alcazaba madrileña fue fundada entre 850 y 886 por el emir de Córdoba Muhammad ben Abd al-Raahman ${ }^{1}$, en el primitivo recinto militar de la ciudad islámica, Mayrit, siendo el germen de la villa que paulatinamente crecería en su entorno. Se fortifica la plaza dotándola de una función de vigilancia de importante trascendencia militar en la entonces conocida como Marca Media. Los estudios arqueológicos han venido a confirmar que esta primitiva alcazaba se había levantado en una ubicación dominante hacia Poniente, el Norte y Levante, convirtiéndose en el principal baluarte defensivo de la villa, guarnecido por el lado Oeste gracias a un fuerte desnivel sobre el río Manzanares. En sus inmediaciones se levantaría en época cristiana el Alcázar Real, estando separados ambos por el "Campo del Rey"2.

Este castillo cristiano en el período bajomedieval estaba vinculado con los lienzos amurallados que protegían la ciudad, formando parte de la propia muralla³. Elías Tormo en 1945 escribía que ésta se cerraba por Poniente en el alcázar y -citando a Quadrado- añadía que dicha cerca era de 12 pies de ancho con grandes cubos, torres, barbacanas y fosos ${ }^{4}$. Se describe este primitivo alcázar como un edifício de planta rectangular con cuatro torres semicirculares en su lado Oeste, dos grandes torres cuadradas al Sur y otra gran torre cuadrada en el ángulo Noroeste ${ }^{5}$.

Sucesivas remodelaciones evidencian su deterioro en época altomedieval. En efecto, a partir del siglo XIV se suceden las referencias sobre remodelaciones encargadas por los reyes. Según Tormo las torres de Poniente tenían mayor antigüedad: semicilíndricas y altas, como las de la muralla. Añade, recogiendo las palabras de Mesonero Romanos, el hecho de una segura remodelación en el siglo XIV de manos de don Pedro de Castilla, que también se encargaría de ampliarlo, seguido por Enrique II siendo que "a consecuencia de las notables obras verificadas por ellos, pudo el Alcázar servir de mansión a los reyes de Castilla". Cuenta León Pinelo que en 1390 el rey León "mandó reedificar las torres del alcázar real, que el tiempo tenía mal tratadas"; durante el reinado de su hijo Enrique III "el doliente", en torno a 1405, se levantaron algunas nuevas torres para que "le hermoseasen" , con el objeto de adecuarlo a su función como residencia regia y "para depositar sus tesoros" ". De este momento parece datar la Torre del Homenaje en el Sudeste, dominando el patio de armas.

\section{Las obras de Juan II y Enrique IV}

Con los últimos monarcas de la Casa de Trastámara el alcázar madrileño alcanzará un gran protagonismo como aposento regio, convirtiéndose en una de las residencias reales más destacadas de la segunda mitad del siglo XV castellano9. Fue objeto de varias remodelaciones para

\footnotetext{
1 Montero Vallejo, 1985: 1011. Barbeito, 1992: 1.

2 Para Tormo, Martín González, Díez del Corral, Gerard o Barbeito, el alcázar cristiano hunde sus orígenes en el mismo edificio musulmán. Por el contrario, trabajos arqueológicos convienen en resaltar la diferencia entre la obra musulmana y el castillo cristiano. Véase VALDÉs FernánDEZ, 1992: 152-154 y AA.VV., 1998: 22.

3 Barbeito, 1992: 8. Díez del Corral, 1994a: 133. Una opinión contraria en Ungorri CASAdo, 1954: 49. Obras en la muralla del alcázar documentadas en Gómez MARTíneZ, 1992.

4 TORMO, 1945: 5.

5 VALDÉS FERNÁNDEZ, 1992: 152.

6 TORMO, 1945: 107.

7 LeÓN Pinelo, 1971: 41, 44.

8 De nuevo Tormo, citando a Mesonero Romanos y sus capítulos publicados en el Semanario Pintoresco Español (TORMO, 1945:107)

9 LAdero Quesada, 2001: 25.
} 
adaptarlo a tal fin. Juan II será "el monarca responsable del acondicionamiento del antiguo castillo en una residencia adecuada al nuevo gusto del siglo $\mathrm{XV}$, basado fundamentalmente en una idea de lujo y esplendor" 10 . Así sirvió de escenario a las cortes abiertas en Madrid el 10 de marzo de 1419 y existen referencias de su uso frecuente en este período como aposento regio ${ }^{11}$.

Este uso continuado del edificio propició el que por primera vez exista constancia documental de maestros encargados de su mantenimiento. Es un momento decisivo en la historia de la fortaleza dotada a partir de entonces de significativas salas destinadas al ceremonial cortesano, como haría el mismo monarca en el alcázar segoviano, el otro edificio fundamental para los Trastámara. De hecho, fue Juan II el que hizo construir las estancias más relevantes del madrileño, inspirándose para ello en el segoviano ${ }^{12}$. En este contexto puede datarse la torre del lado de Poniente, ahora cuadrada y conocida como la "Cuadra Dorada", en la zona dedicada a las salas de protocolo de nueva construcción. Esta primera Torre Dorada, además de tener una rica decoración como refleja su apelativo, se convierte en un elemento importante para la articulación de los diferentes niveles en altura del edificio y entre espacios tan diferentes como el jardín, la planta baja y las salas ceremoniales ya en la planta noble, el corredor del jardín, etc. ${ }^{13}$

Se incluye en esta etapa también la Capilla Real consagrada en 1434 y realizada por el cantero Juan García de Paredes ${ }^{14}$. Se trataba de una capilla construida en el lienzo oriental del patio de armas. Su cabecera y una nave rectangular (de 19,5 $\mathrm{m} \times 7,8 \mathrm{~m}$ ) estaban cubiertas por una cúpula dorada de mocárabes y una armadura de par y nudillo. Al Norte de la capilla, y cerrando este lienzo oriental, se encontraba la única escalera de acceso a la planta noble, una escalera que suponemos claustral y que más tarde Alonso de Covarrubias transformaría en doble claustral. Por ella se accedía a la planta principal del alcázar; al Norte se encontraban las salas de aparato que se abrían al llamado "corredor del cierzo". Una de estas salas, la principal, era la conocida como "Sala Rica" que tenía una longitud aproximada de $22,5 \mathrm{~m}$. y estaba cubierta con un artesonado de par y nudillo con faldones y pintada en oro y carmín. Sus muros estaban recubiertos de yeserías y tapices. En ella, en 1434 bajo un dosel de brocado y un león manso a los pies, Juan II recibía a los embajadores del rey de Francia ${ }^{15}$.

En ese mismo ala estaba además la antecámara redecorada por Enrique IV después del terremoto de $1466{ }^{16}$. En la crujía Oeste estaba la "Cámara Privada" del rey, próxima a la "Chimenea

10 DíEz del Corral, 1994a: 133.

11 Tormo, 1945: 108. Pinelo añade que en 1420 el rey ordenó la fundación de un hospital en las proximidades del alcázar (LEÓn PINELo, 1971: 45). En 1422 fue puesto preso el infante de Aragón, don Enrique, "en una torre sobre la puerta del alcázar y Garci Fernández en otra que estaba á la parte del campo" (León PINELO, 1971: 46). En este edificio se encontraba oculto el tesoro de los "Reyes viejos de Castilla", escondido por el condestable Luna en "lo bajo del entre dos pilares", tal y como lo encontraron al confesarlo Fernán López de Saldaña a Juan II para granjearse el favor real perdido tras su amistad con el Luna (Cit. FerRandis, 1943: XII-XIII. Agradezco al Prof. Villaseñor Sebastián este dato).

12 Desde época de Enrique III, especialmente con su viuda Catalina de Lancaster, el edificio sufre una profunda transformación, continuada por Juan II y su hijo. Al primero se debe la construcción de la gran Torre Nueva hacia la antigua catedral y Enrique IV construirá las salas de las Piñas, del Solio y del Cordón, decorada con artesonados mudéjares y cúpula. Pero la obra que más destaca de este período es la remodelación de la conocida como Sala de los Reyes. (Domínguez CASAS, 1993: 312).

13 BARBEITO, 1992: 7.

14 Gerard, 1984: 16; 1983: 275-283.

15 Según la Crónica del Halconero de Juan II "El Rey don Jhoan los rresçibio en la su gran sala de Madrill, asentado en su silla, según requería su estado real”. (CARRILlo De Huete, 2006: 180). Por su parte Pinelo escribe que "el rey estaba en una gran sala del Alcázar en que había colgados seis antorcheros con cada cuatro achas. El rey aguardó en su estrado alto sentado en su silla debajo del dosel del brocado carmesí, la sala cubierta de ricas tapicerías. A los pies tenía el Rey un león manso con un collar de brocado" (León PINELO, 1971: 47).

16 Castillo Oreja, 2001:112.

Arch. esp. arte, LXXXVII, 348, OCTUBRE-DICIEMBRE 2014, 335-350

ISSN: 0004-0428, eISSN: 1988-8511, doi: 10.3989/aearte.2014.21 
de las alcobas" que le separaba de los aposentos de la reina, ya en el ángulo Suroeste. Los cubos de la Torre del Homenaje y del Bastimento seguían en pie, mientras quedaba libre el espacio denominado "Campo del Rey", una zona que los monarcas Trastámara quisieron mantener vacía "con el propósito de ir perfilando un escenario que, a modo de plaza de armas, se entendía fundamental para el desarrollo de las actividades representativas e institucionales ligadas a la Corte, en tanto que proscenio para la exhibición del poder real"17 (fig. 1).

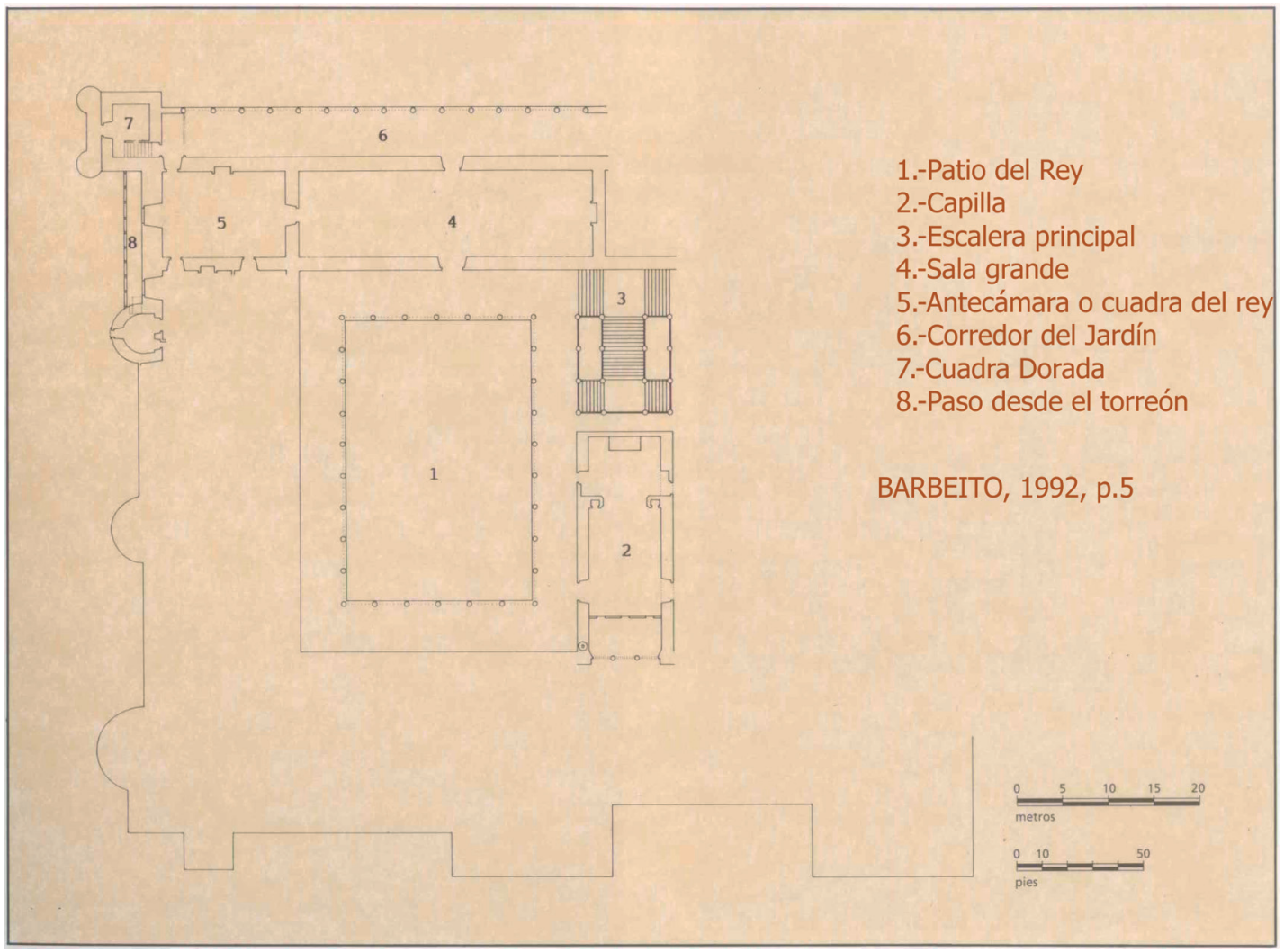

Fig. 1. Reconstrucción de la planta del alcázar en época Trastámara (fuente: Barbeito, 1992: 5).

Las largas estancias de Enrique IV en el alcázar denotan su especial predilección por él y por la propia villa de Madrid $^{18}$. Resulta sobradamente significativo que desde el comienzo de su

17 Lopezosa Aparicio, 2013: 167.

18 Díez del Corral, 1994a: 133-134. En el alcázar nacería su hija Juana en 1462 (bautizada en la Capilla Real) y allí moriría el rey en diciembre de 1474. De 1467 a 1471 el tesoro de la Corona castellana pasó de custodiarse del alcázar segoviano al madrileño (LEÓN PINELO, 1971: 58). Además en Madrid Enrique IV levantaría el monasterio jerónimo de Santa María del Paso "a quien dio grandes rentas e ornamentos muy suntuosos. Y en el Pardo que es a tres leguas desta villa fizo otra casa asaz noble con un bosque poco menos bueno que el de Valsanin -sic-, y en otras partes fizo otros hedifiçios asaz suntuosos". (cit. Crónica anónima de Enrique IV de Castilla, 1454-1474, 1991: 478). Véase RÁBADE OBRADÓ, 2009. Además, como una prueba más de su afecto a la villa, la concede el título de "noble y leal" y en 
reinado en 1454, exista constancia documental de la existencia de un maestro de obras de dicho alcázar. Era "maestre Yuça de Segovia". Le sigue en el cargo su hijo Maestre Lope, confirmado en el puesto por el monarca en 1474, año en que ordena que se le paguen 3.050 maravedíes como parte de su salario anual por dicho puesto. Parece que Maestre Lope también trabajó en El Pardo y se le cita en 1482 como "maestro que fue de las obras del Rey Don Enrrique que santa gloria aya" 19 .

\section{Las obras durante el reinado de los Reyes Católicos}

La documentación no ha evidenciado nuevas obras en el alcázar madrileño hasta el año de 1493, una fecha similar a las mejoras realizadas en otros importantes alcázares castellanos como el segoviano o el sevillano ${ }^{20}$. Los gastos en la alcazaba madrileña no son tan importantes, y están más relacionados con lo ocurrido en Segovia; en 1493 se registra en la Pagaduría General de Hacienda el apunte de una libranza de 300.000 maravedíes para obras en la fortaleza de Madrid ${ }^{21}$, sin que sepamos en que fue empleada tan importante cantidad, la más alta de cuantas se invertirán en este edificio en este período. Posiblemente este gasto estaría en relación con las necesarias reformas que requeriría la presencia de los monarcas que pasarían allí el invierno de 1494.

Mientras las estancias reales en el castillo se espaciaban, el entorno del viejo alcázar continuaba su actividad vinculado a la de la propia villa madrileña. Parece deducirse de las fuentes que se compraban solares en su entorno ${ }^{22}$ y que en 1499 el concejo tomaba el acuerdo de intervenir pues "cerca de los dihos alcaçares se hacia muladar y es en mucho agravio de los dichos alcaçares", por lo que deciden su retiro. El conocido como "Campo del Rey" continuaba sirviendo como escenario de corte para hacer alardes militares, a la vez que existen noticias de que se habían levantado en su entorno nuevas construcciones ${ }^{23}$.

El 20 de junio de 1502 los Reyes Católicos ordenaban a su contador Martín de Salinas que entregase 560.000 maravedíes al contino Pedro de Malpaso para que los distribuya entre las obras de los alcázares de Madrid, Toledo, la casa del Bosque de Segovia y el monasterio de San Mar-

1463 le otorgará el derecho de mercado franco, destacando su celebración “...en la mi plaça questa delante de los mis alcázares...". Cit. Montero VALLejo, 1985: 1021.

19 Domínguez Casas, 1993: 62.

20 En septiembre de 1494 se daba orden de librar 300.000 maravedíes para las obras y reparos del alcázar de Segovia (Domínguez CASAS, 1993: 317). Un mes después se ordenaba que de este dinero librado para las obras de reparación del alcázar de Segovia se abone directamente a Pedro de Malpaso, alcaide del bosque de la ciudad de Segovia, la cantidad de 16.860 maravedíes que se le adeudan de las obras realizadas. (Archivo General de Simancas, Cámara de Castilla, Cédulas, 1, 173, 1). Los Reales Alcázares de Sevilla reciben una importante dotación para sus obras ya en la temprana fecha de 1478, los 100.000 maravedíes mandados librar en 1497 y la relevante campaña de obras de 1502 a 1505 con un monto total que ronda los dos millones de maravedíes al incluir también las obras en las atarazanas de la ciudad (ANDrÉs DíAz, 2004: 202). Sobre los Reales Alcázares de Sevilla en este período Morales Martínez y SERRERA Contreras, 1999: 69-77 y Domínguez CASAS, 1993: 402 y ss. En estos años, además de las obras documentadas por Domínguez Casas, puede citarse ahora la importante intervención de los Reyes Católicos en Aranjuez, construyendo el denominado "Quarto Nuevo" en dos campañas que rozaron un gasto total de casi un millón de maravedíes (ALONSo RuIz, 2012: 16-35).

${ }^{21}$ LADERO QUESADA, 2002: 491.

22 En septiembre de 1498 el concejo otorga carta para el marqués de Villena sobre los solares del alcázar del campo del rey, "si los pago a los dueños d'ellos". Cit. Libro de acuerdos del concejo madrileño. Tomo IV. 1498-1501, 1982: 69.

23 En marzo de 1502 se ordenaba que "que se pinte lo del campo del rey, que se a edificado agora e que sea a vista de los dichos señores corregidor y regidores". Cit. Libro de acuerdos del concejo madrileño. Tomo IV. 1498-1501, 1982: 117 y Tomo V. 1502-1515, 1987: 17 y 23.

Arch. esp. arte, LXXXVII, 348, OCTUBRE-DICIEMBRE 2014, 335-350

ISSN: 0004-0428, eISSN: 1988-8511, doi: 10.3989/aearte.2014.21 
tín de la Zubia en Granada; de ellos concretamente 60.000 maravedíes serían para "çiertas obras que se an de hacer en los Alcáçares de Madrid"24. Entre ese mes y noviembre ya se habían realizado algunas de estas obras: se habían contratado a maestros, peones y oficiales desde septiembre y en noviembre se pagaba a Jerónimo de Palacios "maestro de carpintería de su alteza" 25.066 maravedíes por "çiertos atajos de madera e escaleras... e de otros pertrechos que compro e gasto e labro en los aposentamientos de los alcaçares de Madrid", colocando en las ventanas lienzos encerados ${ }^{25}$. En febrero de 1503 se pagaba de nuevo a Palacios 17.837 maravedíes que se habían gastado entre noviembre de 1502 y enero del siguiente año "en algunos hedifiçios e reparos, que hizo en el aposentamiento del alcázar de Madrid de su alteza"26.

Por las escasas referencias a las obras realizadas se puede deducir que se trataba de adecuar el edificio a las próximas estancias de los monarcas que llegan a Madrid el 9 de diciembre. Fijarán allí su residencia entre esa fecha y el 14 de enero de 1503, primero acompañando a los herederos Felipe y Juana y luego solo con ésta, tras abandonar el archiduque Madrid en diciembre rumbo a los Países Bajos. La reina vuelve al alcázar entre el 15 de julio y el 4 de agosto de 1503, siendo de nuevo Jerónimo de Palacios el encargado de aderezar su habitación ${ }^{27}$. En 1503 consta Gonzalo Fernández (antes Maestre Hazán) como maestro del alcázar, responsable último de estas obras ${ }^{28}$ y en abril de 1504 le acompaña en el cargo otro moro bautizado como Diego Hurtado. En esa fecha, 2 de abril, se pagan a cada uno 8.000 maravedíes por su cargo de "maestros de las obras del alcázar de Madrid", declarando que desde ese día en adelante no se les paguen más quitaciones salvo los días trabajados en dichas obras. Ello demuestra, según Domínguez Casas, que desde 1504 se quiere modificar el sistema, racionalizando el gasto a lo realmente trabajado ${ }^{29}$.

\section{Las obras de Fernando el Católico}

Las obras de mejora y acondicionamiento del viejo edificio debieron tener cierta continuidad durante los siguientes años pues en 1505 consta que catorce esclavos "que se trajeron de Lagos" fueron adjudicados a estas obras ${ }^{30}$. Debía ser ya por entonces un edificio en gran estima para la Corona pues el Consejo Real escribía al concejo madrileño el 13 de octubre de 1506 ordenándole que "guarde con gran cuidado el Alcázar y lo tenga abastecido de todo género de alimentos, municiones y gente" 31 .

Pero el hecho cierto es que tras la muerte de la reina, la presencia de Fernando el Católico no está documentada en el alcázar hasta 1510. En ese año residirá largas temporadas en él, volviendo en 1513 y $1515^{32}$. Si bien parecía que Fernando el Católico no había intervenido en el alcázar,

24 Domínguez CASAS, 1993: 323.

25 Cuentas de Gonzalo de Baeza. Tesorero de Isabel la Católica, 1956: 566.

26 Cuentas de Gonzalo de Baeza. Tesorero de Isabel la Católica, 1956: 579.

27 Domínguez CASAS, 1993:324.

28 Domínguez CASAS, 1993: 63. Existen referencias al posible trabajo en el alcázar de otro maestro moro bautizado en 1502, Abrahen de Sant Salvador, un reconocido alarife que en 1482 había tasado la obra de la "puente toledana". Se supone su presencia en el alcázar pues en febrero de 1502 consta en el libro de acuerdos del concejo "la ropa que en el alcaçar tenian de los moros e se an convertido que se los buelva", justo después de un asiento que da noticia de su conversión (cit. Libro de acuerdos del concejo madrileño. Tomo V. 1502-1515, 1987: 16).

29 Domínguez CASAs, 1993: 63.

30 ANDRÉS DÍAZ, 2004: 1030.

31 Catálogo de los documentos del Archivo de la Villa. Reyes Católicos (1475-1504), 2004: 23.

32 En 1510 está en el alcázar entre el 13 de febrero y el 4 de abril acompañado por su nieto el infante don Fernando y el Cardenal Cisneros. Vuelve el mismo año entre el 24 de septiembre y el 3 de noviembre, y luego en Navidad 
en 1998 Jesús Herranz daba a conocer un documento sobre las obras efectuadas en el alcázar poco antes de $1511^{33}$. Se trataba de la rendición de cuentas el 11 de enero de ese 1511 del alcaide del alcázar, Francisco de Vargas, de los 50.000 maravedíes que su majestad había proveído para reparar el edificio. Ahora, ese documento se complementa con otro mucho más extenso en el que Francisco de Vargas, en ese mismo día, rinde cuenta esta vez de 150.000 maravedíes destinados a estas obras ${ }^{34}$.

Ambos documentos se complementan: en algunos casos se repiten partidas idénticas, en otros están redactadas de forma diferente tratándose de la misma partida ${ }^{35}$, y en tercer lugar, el nuevo informe aporta datos no contenidos en el publicado por Herranz. La razón es que ahora el monto de la cantidad a justificar por el alcaide asciende al triple, 150.000 maravedíes y no a los 50.000 maravedíes del primer memorial. Todas las obras fueron ordenadas por Fernando el Católico ya que en la cédula real se contiene que "yo mande que se hisiesen en los dichos alcaçares quando ove de venir a la dicha villa de Madrid" 36 en 1510, por lo que el margen temporal para la realización de las mismas debió ser muy escaso pues estaban realizadas en enero de 1511 .

Estamos ante obras de consolidación y reparaciones, pues la liquidación de cuentas deja entrever el deterioro en el que se encontraba el viejo alcázar madrileño; se habla constantemente de "reparos" y se incluyen expresiones como arreglos en los camaranchones "que estauan hundidos", la sala de la reina "estaua toda cayda e derribadas las paredes", "reparose vn corredor que estaba hundido junto a la puerta de la yglesia de los principales de la casa", "en el aposento de la camarera a la parte del ryo estaua desolado e caydos los retraimientos", "en el aposento del camarero del rey que es a la parte de las cozinas estaua todo desolado e destablado", etc. Valga para ilustrar el estado del alcázar en este momento que se gastan 5.000 maravedíes en limpiar "toda el alcaçar con peones... y echaron fuera toda la basura e tierra" 37 .

Prácticamente todos los espacios del alcázar están necesitados de reforma: ambos documentos constatan intervenciones de consolidación tanto en el lienzo Norte y el ángulo Noroeste, el lienzo de la vega del río con los cubos y las estancias destinadas a personal de servicio, el ángulo Suroeste - donde se localizan los aposentos de la reina-, la zona meridional -Torre del Homenaje y Torre del Bastimento- y la zona oriental -con la iglesia-. Uno de los espacios necesitados de mayores arreglos es el ángulo del Cuarto Real, con la Sala Real que estaba "destablado todo el estrado grande y se compraron tablas de nuevo para hazerle", y se hizo necesario recomponer sus paredes y suelos ${ }^{38}$. Entre los cubos del lienzo occidental se encontraban las habitaciones de los camareros reales, el del rey y la de la reina, y parece que existían unas cocinas ${ }^{39}$, mientras

(del 9 de diciembre de 1510 al 7 de enero de 1511). La estancia más larga se produce entre el 5 de noviembre de 1513 y el 20 de mayo de 1514. Vuelve entre el 29 de octubre y 7 de noviembre de 1515 (Domínguez CASAS, 1993: 323-324).

33 Herranz, 1997-1998: 117-132. El documento de 1511 en el Archivo General de Simancas, Contaduría Mayor de Cuentas, 1. ${ }^{a}$ época (en adelante AGS, CMC, 1. a ép.) Leg. 1282, exp. 7.

34 AGS. CMC, 1. ep. Leg. 303, exp. 11.

35 Por ejemplo, en el documento de Herranz se recoge "hizose la sala de la reina de nuevo porque estaba toda hundida cayda derribadas las paredes una tapia en el alto, caño de la chimenea, enchir el suelo de yeso", y en el nuevo "hizose la sala de la reyna de nuevo porque estaua toda cayda e derribadas las paredes vna tapia en alto e avia maderas encima pa(ra) hazer la dicha sala e començada a labrar e non avia tablas ni otro pertecho segund nosotros lo vimos" (fol. 3 vto.). Cuando la partida coincida entre ambos informes, se hará constar en nota.

36 AGS. CMC, 1. a ep. Leg. 303, exp.11, fol. 1.

37 AGS. CMC, 1. a ep. Leg. 303, exp.11, fol. 6 vto.

38 AGS. CMC, 1. ${ }^{\text {a ep. Leg. 303, exp.11, fol. } 6 .}$

39 Partida que detalla que se gastaron 2.000 maravedíes en "aposentamiento del camarero con la torre de abona". AGS. CMC, 1. a ep. Leg. 303, exp.11, fol. 2. Cit. en Herranz, 1997-98: 126 que añade que se trata de la Torre Bahona. En el fol. 6. se indica que el aposento del camarero "es a la parte de las cocinas".

Arch. esp. arte, LXXXVII, 348, OCTUBRE-DICIEMBRE 2014, 335-350 ISSN: 0004-0428, eISSN: 1988-8511, doi: 10.3989/aearte.2014.21 
que el cuarto de la camarera se encontraba en la parte del río $0^{40}$. La Sala de la Reina en el Sureste también prácticamente se rehace entera "porque estaua toda cayda e derribadas las paredes"41, levantándolas y rehaciendo el tejado. Para ello se habla de albañiles encargados de hacer la obra de la chimenea y se construye una escalera nueva; también se contiene una referencia a un mirador hacia la vega del río en los cuartos de la reina, como ya ocurriera en la remodelación de los palacios de la Alhambra en época de los Reyes Católicos ${ }^{42}$. En este ángulo Sureste se trabaja en el cuarto de la escalera "con el corredor de hacia el campo del rey con la torre del omenaje unas tres mil tejas que pudieron costar 2.400 maravedíes"43.

En el patio se trastejan sus cuatro corredores y se colocan cintas y respaldos en sus paredes. Esta zona debía estar muy deteriorada pues se indica que "reparose vn corredor que estaba hundido junto a la puerta de la ygl(es)ia de los principales de la casa"44. En otra parte del documento se habla de la construcción de dos cocinas nuevas; en esta zona de cocinas fue necesario colocar grandes vigas para sufrir la carga de los tejados -que también son reparados con teja nueva-, así como construir unos aparadores y solar de ladrillo los hogares ${ }^{45}$. Debía tratarse de una zona muy deteriorada pues el documento llega a afirmar que en ese "quarto de hacia el campo del rey" se cubre un cubo "questaba fecho terrado" 46 . En esta zona frente a la Torre de Bastimento había otras cocinas, denominadas en el nuevo informe "del ynfante", a lo que se añade a continuación que "se hizo un aparador en la cocina de la infanta" 47 .

$\mathrm{Al}$ exterior, el puente levadizo del alcázar también fue reparado con tablones ${ }^{48}$ y en los "poyos de la plaça" se gastan 2.000 maravedíes. Este es el único punto donde se cita piedra en toda la obra al decir que "una pared que se hizo en la plaça porque era piedra pudo gastar en maestros, peones, cal y ladrillo, arena 5.000 maravedíes"49.

Todas estas obras de reparos y consolidación de muros y tejados, que evidencian el deterioro del alcázar en estas fechas, fueron tasadas por "maestre diego alarife de la villa e la maestre antonio maestro mayor de los dichos alcaçares e alarife de la dicha villa e ambos a dos maestros alvanyres". Estiman que lo realizado alcanza la cantidad total de 154.174 maravedíes, dando finiquito a la liquidación el 14 de enero de $1511^{50}$.

\section{Obras del período de Carlos V}

Para el viejo alcázar madrileño la llegada de un nuevo monarca no supuso en un primer momento, un gran cambio. Las obras que se realizarán durante los años veinte y treinta evidencian que no se planteó un nuevo palacio, sino una remodelación del antiguo, reflejando la valoración del edificio medieval al conservar las espaciosas habitaciones de aparato ${ }^{51}$.

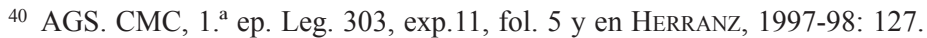

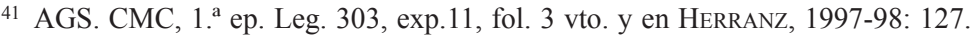

42 AGS. CMC, 1. a ep. Leg. 303, exp.11, fol. 2 vto. y en Herranz, 1997-98: 127. Se habla de trastejar el "cuarto e recuarto de la parte del río con el mirador de la Reyna".

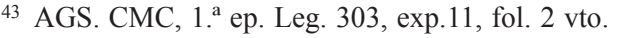

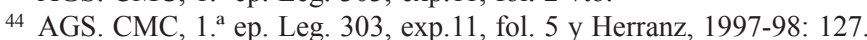

${ }^{45}$ AGS. CMC, 1. ${ }^{a}$ ep. Leg. 303, exp.11, fol. 4-5.

${ }^{46}$ AGS. CMC, 1. ${ }^{\text {a }}$ ep. Leg. 303, exp.11, fol. 6 vto.

47 "en el quarto que afrenta con la torre del bastimento en vnas cámaras sobre la cozina del ynfante se hisieron ciertos suelos de yeso..." por 1.000 maravedíes. AGS. CMC, 1. a ep. Leg. 303, exp.11, fol. 6 vto.

48 Adobar la puente levadiza "quando vino el rey otra vez", AGS. CMC, 1. a ep. Leg. 303, exp.11, fol. 6 vto.

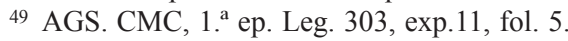

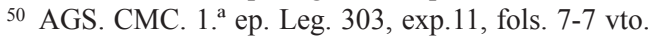

51 Díez del Corral, 1994b: 135.
} 
Si nos centramos en las obras realizadas al comienzo del reinado del monarca, veremos cómo insisten en la continuación de las obras de reparos anteriores. El sistema de trabajo reflejado en la documentación consiste en la presencia de un maestro mayor de dichas obras (el maestre Antonio ya citado en el período anterior) y un sobrestante de las mismas (Pedro de Gálvez). Las cuentas serán firmadas por el maestro junto al alcaide (Francisco de Vargas); con este sencillo organigrama se realizarán las obras durante los años 1525, 1527-28, 1529 y 1531 . Pero incluso antes de estas fechas, apenas llegado a Castilla el nuevo rey, en agosto de 1518 éste expedía una cédula a Vargas para que pagase 1.200 ducados de oro repartidos en tres años para el reparo del alcázar que se usarían en "labrar y pintar ciertas salas" 52.

En 1525 el alcaide del alcázar madrileño, Gómez de Villafuerte, realizaba el cargo y descargo de los dineros recibidos "para las obras de dicho alcalçar" correspondientes al "servicio de cordova" del año 1520, lo que indica que desde esa fecha -al menos- se estaba procediendo a recabar fondos para tal tarea. El cargo suma la reducida cantidad de 24.874,5 maravedíes. La data y el alcance se firman en Madrid en noviembre de $1525^{53}$; por esta cuenta sabemos que únicamente se gastaron "en maestros y peones y madera y cal y yeso y teja y en otros materiales en reparar el dicho alcaçar segund lo dio por menudo" la cantidad de 12.666 maravedíes, quedando de alcance la cifra de 12.208,5 maravedíes.

De nuevo dos años más tarde se interviene en el alcázar con motivo del fuego provocado en "en tiempos quel rey de Francia estuvo en ellos el año de 1526". Estas noticias sobre las obras realizadas en 1527 fueron publicadas por Herranz y ahora la localización del nuevo expediente permite completar dicha información ${ }^{54}$. El cargo del dinero recibido por el alcaide Villafuerte suma 225.000 maravedíes "para que se gastasen en las obras y reparos de lo que se quemo en los dichos alcaçares al tiempo que el rey de françia estuvo en ellos". El documento alude a la prisión de Francisco I en Madrid tras su derrota por las tropas españolas en la Batalla de Pavía en 1525. Entrará en Madrid el 12 de agosto de 1525 y permanecerá en la villa y en su alcázar hasta mediados de febrero de $1526^{55}$.

Volviendo al alcázar madrileño, la orden para iniciar las obras procede de una cédula real firmada en Granada el 7 de diciembre de 1526. En dicho documento se especifica que se debía cobrar de dicha ciudad la cantidad de 431.635 maravedíes y entregar 231.000 a Villafuerte para que los aplicase en tal tarea, ordenando que las nóminas de lo gastado debían ir firmadas del propio Villafuerte y de "maestre Antonio de Madrid nuestro maestro mayor de las obras de los dichos alcaçares" y que se debían entregar los otros 200.000 maravedíes a Antonio de Malpaso "nuestro alcaide del bosque de segovya pa(ra) que los gaste en el rreparo y cerca del dicho bosque por la horden y segund el dicho malpaso ha gastado otras quantias de mrs para las obras de la casa del dicho bosque" ${ }^{56}$. A diferencia de lo que ocurrirá diez años más tarde, aún en este

52 Domínguez Casas, 1993: 326.

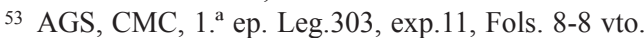

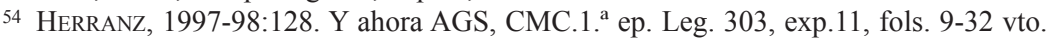

55 En Madrid, durante un breve período, residirá en la casa de Fernando Luján en la plazuela de la villa, alojándose después en el alcázar como señalan Gonzalo Fernández de Oviedo, Prudencio de Sandoval y Pedro Salazar de Mendoza. Parece que ya residía en el castillo cuando se firma el Tratado de Madrid (14-I-1526). El 15 de febrero Francisco I estaba todavía en Madrid. De allí los dos reyes partieron para Illescas (Toledo) y después se inicia el viaje de vuelta a Francia, llegando el 8 de marzo a Fuenterrabía. FERNÁNDEZ ÁlVAREZ, 1999: 318-322. Sobre este asunto han sido de gran ayuda las orientaciones del prof. José Ignacio Fortea. El incendio seguramente obligaría a buscar otra residencia al prisionero mientras duraron las reparaciones. El lugar escogido pudo ser la cercana residencia de la Casa de Campo de la familia Vargas por lo que el Rey francés pudo conocer las singulares características espaciales de esta villa suburbana, que más tarde intentó reproducir en el Chateau de Madrid (MARÍAS Y GERARD, 1991: 26-35).

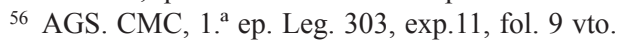

Arch. esp. arte, LXXXVII, 348, OCTUBRE-DICIEMBRE 2014, 335-350

ISSN: 0004-0428, eISSN: 1988-8511, doi: 10.3989/aearte.2014.21 
momento no existe por parte del emperador la idea de centralizar la organización de las obras reales.

La cuenta total de lo gastado en estos reparos asciende a $207.060,5$ maravedíes ${ }^{57}$ y a partir de ahí el documento incluye el detalle "por menudo" de dichas obras semana a semana, desde el miércoles 21 de agosto de 1527 en que "se comenzo a labrar el quarto quemado" hasta finales de febrero de 1528 (aunque se citarán unas pequeñas obras entre enero y abril de 1529). Cada plana está firmada por "maestre Antonio" y Villafuerte, el alcaide. Como sobrestante de la obra actúa Pedro de Gálvez, "viendo lo que hazian peones y maestros todos los días que labraron y asi mismo entendio en traer el yeso y los otros pretechos -sic- que fueron menester para la dicha obra desde xxi de agosto que se comenzó hasta xxix de hebrero a razón de vn real cada dia se le dieron tres myll y ochocientos y ocho mrs"58 (fig. 2).
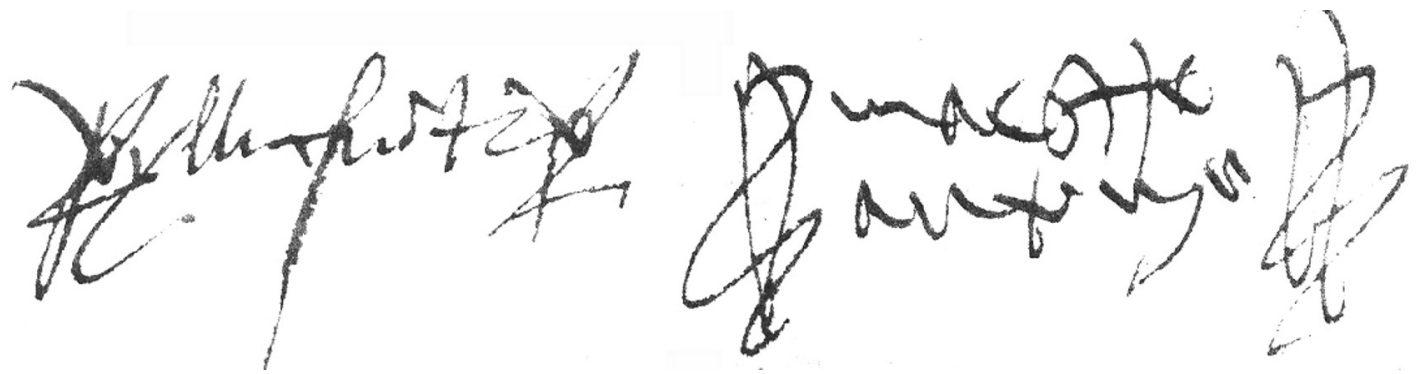

Fig. 2. Firmas de Villafuerte y Maestre Antonio en las cuentas de 1529 (AGS. CMC, 1. ep. Leg. 303, exp.11).

Como cualquier comienzo de obra lo primero fue el abastecimiento de materiales ${ }^{59}$. El trabajo se organiza combinando los sistemas de destajo y trabajo a jornal. En septiembre se da a destajo "la quadra de Ryestre y la otra quadra grande" a Villafuerte, maestro carpintero "pa(ra) que les echase sus maderamientos de vigas pies sobre sus soleras y guarneçidas de cinta y sactino y tabiques y entablado de sus tablas achylla traviesa todo muy bien labrado e azepillado" por 10.000 maravedíes. A comienzos de noviembre se da a Antonio Syllero el destajo de blanquear ese mismo espacio "la quadra del ristre y la quadra grande y la quadra cabeza y una chimenea en esta quadra" cabeza por 10 ducados. Otro destajo era el que "diose Alonso de Madrid pintor por dar color a los maderos del halania y de otro retrete del requarto porque eran los maderos biejos de los que quedaron por quemar para que veniese con las tablas y çinta y sactino que le echaron" 475 maravedíes ${ }^{60}$. Además, se organiza el trabajo a jornal de dos grupos; dos cuadrillas trabajan a la vez, una ocupada en labrar madera y otra en tareas de trastejado con peones que llegan a sumar una cuadrilla de diez peones y varios maestros ${ }^{61}$. Pese a que esta información resulta útil en aspectos económicos como salarios, apenas aporta datos que nos permitan acercar-

57 AGS. CMC, 1. a ep. Leg. 303, exp.11, fol. 10.

58 AGS. CMC, 1. a ep. Leg. 303, exp.11, fols. 21 vto.-22.

59 Las obras se inician con la marcha "a la ribera" de maestre Francisco a comprar madera, aunque también se cita su compra a varios vecinos de Robledo y Val de Maqueda, toda ella por un valor total de 141.341 maravedíes. La compra de yeso asciende a 11.736 maravedíes, la teja suma 26.444 y los clavos $6.765,5$ maravedíes.

60 AGS. CMC, 1. ${ }^{\text {a }}$ ep. Leg. 303, exp.11, fols. 23-23 vto.

${ }^{61}$ Los que trabajan la madera cobran 2 reales (60 maravedíes) de jornal, mientras que los trastejadores 40 maravedíes; todos los peones cobran 30 maravedíes. Los maestros son Juan de San Martín, Francisco de las Beatas y Pedro de Sydre. 
nos al estado y distribución del viejo alcázar. Podemos deducir de las cuentas que a medida que avanza la obra se citan trabajos en yeso y tareas más específicas como subir la madera para la armadura, subir vigas para la sala, "labrar las vigas de la sala", abrir una ventana, hacer chimeneas, poner umbrales en las puertas, etc.

En 1529 se contrata a un nuevo grupo que también cobra a jornal, encargado ahora del trabajo de la piedra y ladrillo por los maestros Diego de Murga y Francisco de la Vega junto a cuatro peones ${ }^{62}$. Se trabaja en el "quarto junto a la escalera principal", en arreglar el tabique que cayó encima de la capilla, en la escalera que subía al adarve, en el corredor sobre la huerta, mientras otros trastejaban las cocinas y el corredor de la sala de las armas.

El lunes 21 de agosto de 1531 se inician de nuevo los gastos en los reparos del alcázar que duran hasta mediados de octubre ${ }^{63}$. Las obras son de reparación como en ocasiones anteriores, ahora de nuevo en relación "al quarto que se quemo"; se recogen trabajos en el suelo de esta zona "que no se avia hechado cuando se labro porque no hubo tienpo de la venida de la corte", lo que indica que la llegada de la corte en abril de 1529 propició la interrupción de las obras. En esta última campaña el gasto no superó los 10.000 maravedíes.

Concluyen las cuentas Gomez de Villafuerte y el maestro Antonio escribiendo que se necesitan más tejas para la mejora del alcázar; destaca significativamente una de sus últimas frases: se habla de "la nesçesidad de adobar la escalera principal de la dicha alcazar y otras muchas cosas que con pocos dineros se haría y si no se remedia con tiempo serán menester muchos esto dezimos porque no nos pongan culpa del daño que vinyere" 64 .

Jan Cornelisz Vermeyen reproducía este lamentable estado en una estampa dada a conocer por Marías que parece anterior a la reforma de $1536^{65}$ : el lienzo hacia el Campo del Rey como una amalgama de edificaciones de diferentes alturas, mientras poco queda ya de unas ruinosas murallas; aún se observa la parroquia de San Gil tapando la primitiva portada, la techumbre de la Capilla real, los cubos de las Torres del Homenaje y del Bastimento, etc. (fig. 3).

\section{El aggiornamento a partir de Covarrubias}

Pocos años más tarde se tomarán medidas efectivas para evitar el deterioro del edificio; ya no se trata de intervenciones destinadas a grandes o pequeños reparos en el viejo alcázar altomedieval, sino que se procederá a su definitiva transformación como nueva residencia imperial, en la ciudad que ya por entonces se decantaba por convertirse en capital de ese vasto imperio. El proceso de definitiva reforma se inicia en abril de 1536 cuando se ordena al arquitecto Alonso de Covarrubias la transformación del alcázar madrileño ${ }^{66}$, con la creación de un patio anexo al existente con una escalera monumental, detrás de la cabecera de la antigua capilla en la crujía central, que serviría de comunicación entre los dos espacios. Se incluye la regularización de ese viejo patio del alcázar -que desde entonces pasará a llamarse "Patio del Rey"- trazando unas nuevas galerías de arcos de medio punto en su piso inferior y arquitrabadas en el superior ${ }^{67}$. En mayo se contrata la obra de dicha escalera según una traza realizada por el propio Covarrubias ${ }^{68}$ con estructura doble claustral en forma de $\mathrm{H}$-concluida en 1547- que rompe por primera vez

\footnotetext{
62 AGS, CMC.1. a ep. Leg. 303, exp.11, fols. 28-30.

63 AGS, CMC.1. ${ }^{a}$ ep. Leg. 303, exp.11, fol. 30 vto.

64 AGS, CMC.1. ep. Leg. 303, exp.11, fol. 32.

65 MARÍAS, 2000: 207, 217, en especial nota 24.

66 Gerard, 1984: 9; Gómez MartíneZ, 1992: 209.

67 DíEz del Corral, 1994b: 136.

68 Gómez MartíneZ, 1992: 204.
}

Arch. esp. arte, LXXXVII, 348, OCTUBRE-DICIEMBRE 2014, 335-350 ISSN: 0004-0428, eISSN: 1988-8511, doi: 10.3989/aearte.2014.21 


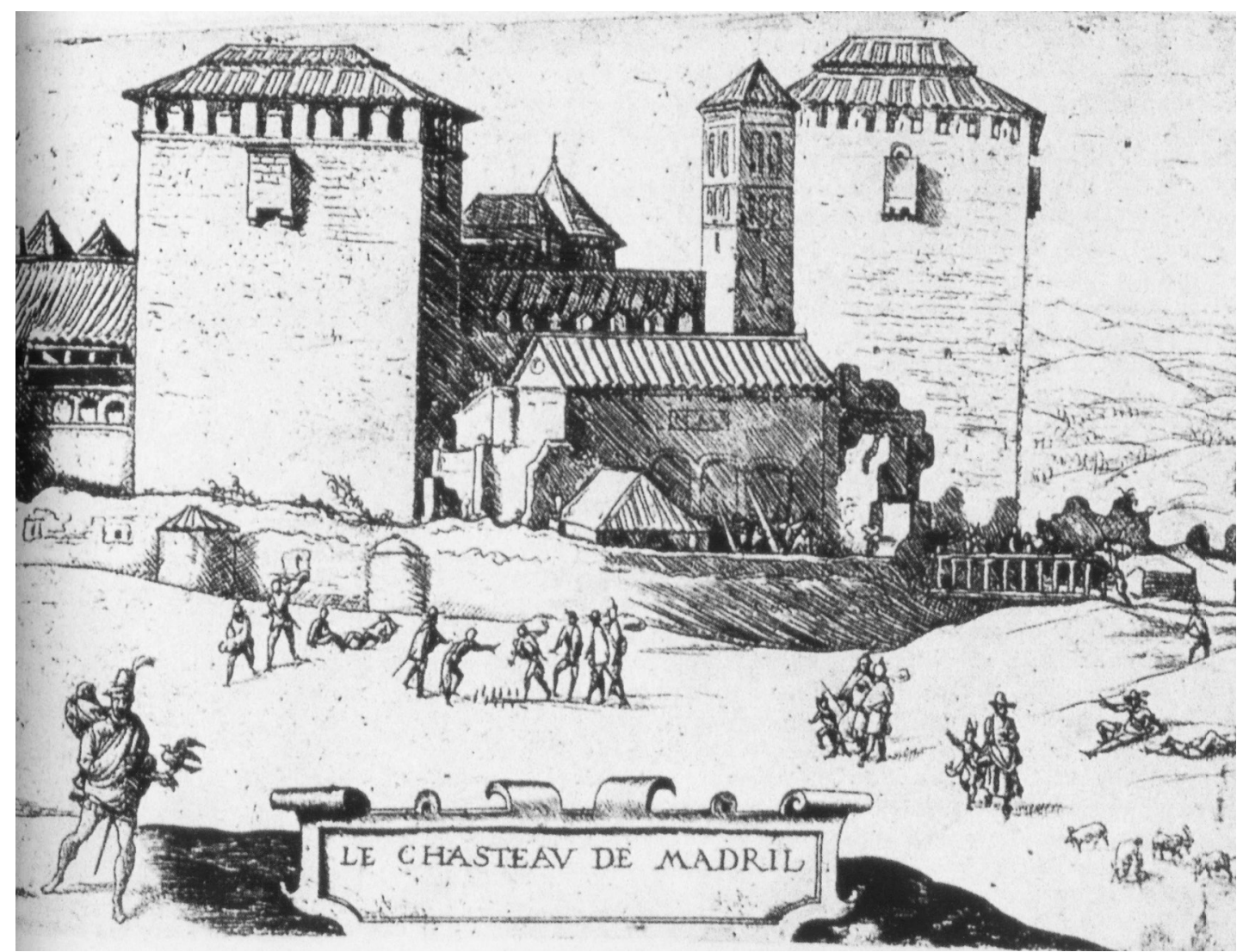

Fig. 3. Detalle de "Le Chasteau de Madrid", estampa de Jan Cornelisz Vermeyen (Metropolitan Museum of Art, Nueva York).

con el tradicional modelo unidireccional e inicia una nueva etapa en las escaleras del renacimiento español ${ }^{69}$.

Aproximadamente año y medio después, el 21 de diciembre de 1537, Carlos V nombra a Luis de Vega y Alonso de Covarrubias para que tengan cargo conjunto en los alcázares de Sevilla, Toledo y Madrid ${ }^{70}$. Con esta orden comienza el aggiornamento de todos los Reales Sitios ${ }^{71}$, dando un paso definitivo en la regularización administrativa uniforme y centralizada de dichas construcciones $^{72}$.

Mientras la reforma del alcázar sigue su curso; la construcción de la nueva plantea la duplicación del patio antiguo, creando ahora el denominado "Patio de la Reina". En relación a este momento constructivo se dibuja el plano del alcázar custodiado en el Ministerio de Asuntos Exteriores, atribuido desde V. Gerard a Alonso de Covarrubias y datado en torno a 1537 y que J.

69 Sobre esta escalera: Gómez Martínez, 1992: 208. Wethey, 1964. Gerard, 1985. Barbeito, 1992: 3-32 y UReÑA UCEDA, 2007: 74-79.

70 Llaguno y Amirola, 1829: II, 3.

71 Gómez MarTíneZ, 1992: 209.

72 Cano de Gardoqui, 2006-2007: 52. 
Herránz retrasa hacia 1542 y relaciona con Gaspar de Vega ${ }^{73}$. En él ya se hace evidente la duplicidad de patios y esa nueva escalera, a la vez que queda recogida la estructura del antiguo alcázar Trastámara con las salas de aparato al Norte y las habitaciones reales en torno al lienzo Oeste con la primera Torre Dorada en el ángulo Noroeste (fig. 4).

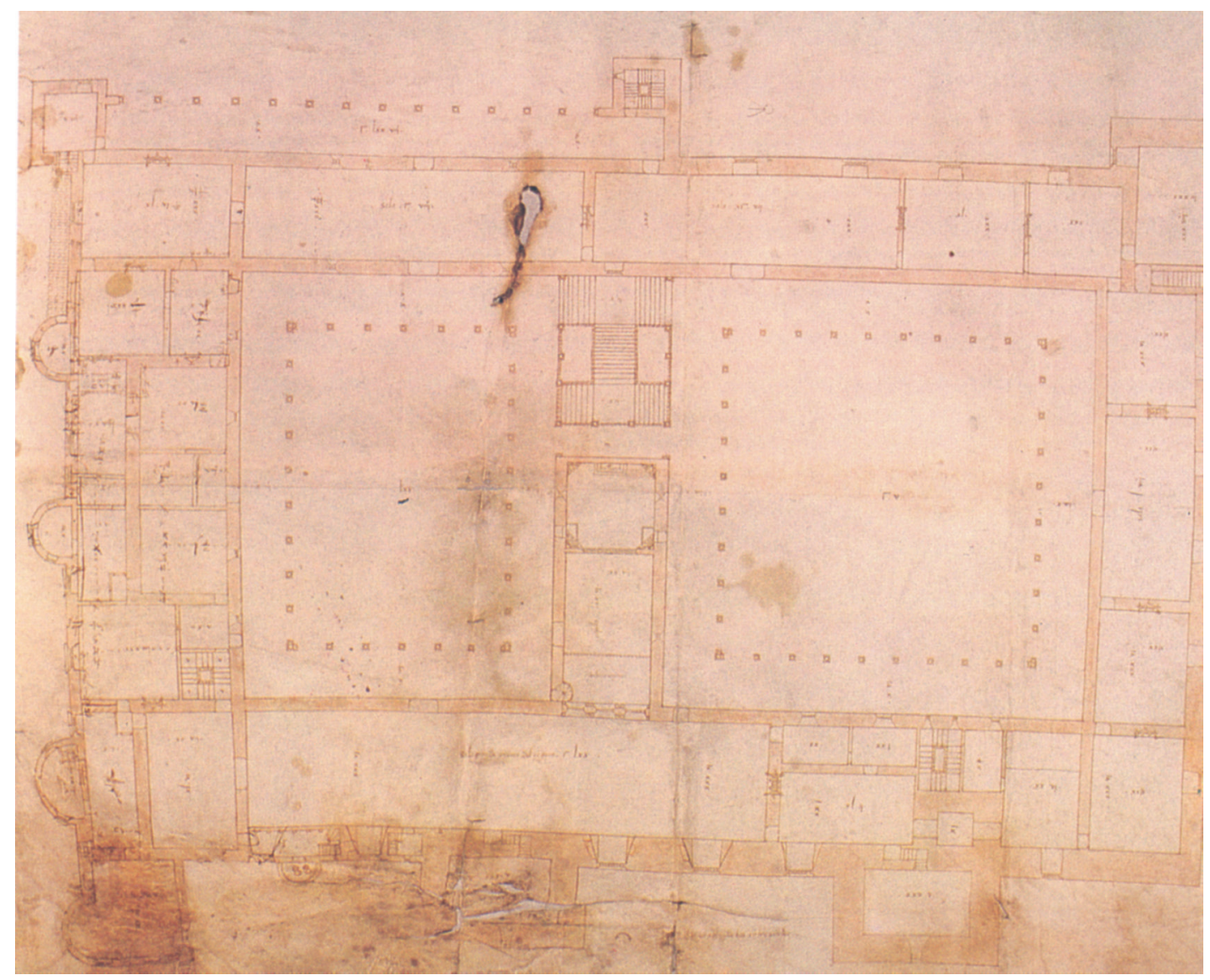

Fig. 4. Plano del alcázar de Madrid (Ministerio de Asuntos Exteriores, Madrid).

Le seguirán las obras documentadas por Cervera Vera: tres contratos de 1540 para mejorar las armaduras de la capilla, la "cuadra" y sala grande, y la construcción de la arquería del Patio de la Reina "a lo romano" 74 . Ahora las antiguas salas de protocolo, con la cámara y recámara, se remodelan de nuevo con trabajos de yesería y carpintería. Además se deben realizar obras en la capilla que erigiese tiempo atrás Juan II, reformando el presbiterio que se hará ochavado, con arco análogo "al arco que está labrado en la capilla de los Reyes, de Toledo", y con dos tribunas para uso del emperador. En este momento también se trabaja en el corredor hacia el jardín y la

73 Gerard, 1984: 20. Herranz, 1997-98: 118 y ss.
74 Cervera Vera, 1979: 59-150; 1994: 45-59.

Arch. esp. arte, LXXXVII, 348, OCTUBRE-DICIEMBRE 2014, 335-350

ISSN: 0004-0428, eISSN: 1988-8511, doi: 10.3989/aearte.2014.21 
torre esquinera, la "Cuadra Dorada", del Noroeste, se repara también con la pintura y el dorado de su armadura ${ }^{75}$ y se la dota de una escalera para comunicar esta zona con el jardín, escalera visible en el dibujo de Wyngaerde, al igual que el corredor exterior que se construye entre esta torre y el primer cubo, también de esta época ${ }^{76}$.

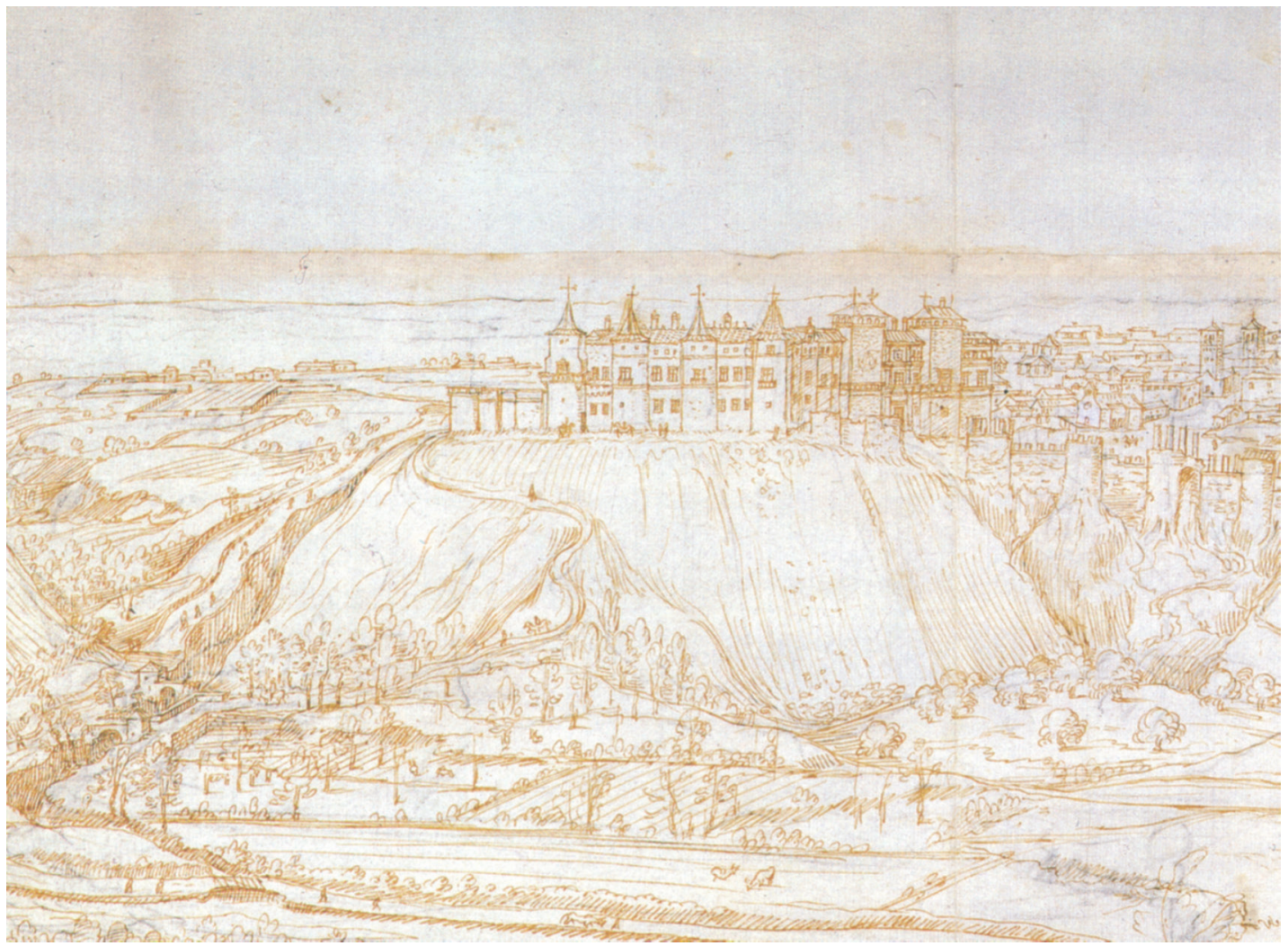

Fig. 5. Fachada del alcázar de Madrid en la Vista de Anton Van der Wyngaerde hacia 1562

(Fte: Kagan, 1986, p. 111).

Como final de esta etapa, en 1543 se encargaba a Gregorio de Bigarny la obra de una nueva portada principal entre las torres medievales del lienzo Sur para el ya palacio real ${ }^{77}$. Con ella concluía el proceso de regularización del palacio y de la propia plaza real como espacio de representación regia ${ }^{78}$. Actuaba así Carlos $\mathrm{V}$ con un "especial cuidado por mantener una continuidad con el viejo alcázar Trastámara, lo que es tanto como decir con los usos y costumbres escritos sobre sus muros por la dinastía anterior"79 (fig. 5).

75 BARBEITO, 1992: 4-5.

76 DíEz del CoRral, 1994b: 138.

77 Estella, 1980: 124

78 LOPEZOSA APARICIO, 2013: 167.

79 BARBEITO, 1996: 53. 


\section{BIBLIOGRAFÍA}

AA.VV., Las murallas de Madrid. Arqueología medieval urbana, Madrid, 1998.

Alonso Ruiz, B., "El Quarto Nuevo de los Reyes Católicos en Aranjuez", en Reales Sitios, Revista de Patrimonio Nacional, año XLIX, n. ${ }^{\circ} 194,2012$, pp. 16-35.

Andrés Díaz, R. de, El último decenio del reinado de Isabel I a través de la tesorería de Alonso de Morales (1495-1504), Universidad de Valladolid, 2004.

Barbeito, J.M., El alcázar de Madrid, Madrid: COAM, 1992.

Barbeito, J.M., "El Alcázar de Madrid", en Palacios Reales en España. Historia y arquitectura de la Magnificencia, Madrid, 1996, pp. 51-66.

Cano de Gardoqui, J.L., "Visitas de don Francisco de Luzón, Gobernador de la provincia de Castilla, a las obras reales de Aranjuez, el alcázar de Madrid y la Casa Real de el Pardo (1548-1549)", en Boletín del Seminario de Arte y Arqueología, 2006-2007, pp. 51-61.

Carrillo de Huete, P., Crónica del Halconero de Juan II, Granada, 2006.

Castillo Oreja, M.Á., "La conservación de un valioso legado: la rehabilitación de los alcázares reales en la política constructiva de los Reyes Católicos", en Castillo Oreja, M.Á. (Ed.), Los alcázares reales. Vigencia de los modelos tradicionales en la arquitectura áulica cristiana. Encuentros sobre patrimonio. Col. Debates sobre arte. Madrid, 2001, pp. 99-128.

Catálogo de los documentos del Archivo de la Villa. Reyes Católicos (1475-1504), Ayto. de Madrid, Madrid, 2004.

Cervera Vera, L., "Carlos V mejora el alcázar madrileño”, en Revista de Archivos, Bibliotecas y Museos, n. ${ }^{\circ}$ 5, 1979, pp. 59-150.

Cervera Vera, L., "Obras en el alcázar madrileño de Carlos V”, en Checa, F. (Dir.), El Real Alcázar de Madrid. Dos siglos de arquitectura y coleccionismo en la corte de los Reyes de España, Madrid: Nerea, 1994, pp. 45-59.

Crónica anónima de Enrique IV de Castilla, 1454-1474. (Crónica castellana). Ed. de M. ${ }^{a}$ Pilar SánchezParra, Madrid, 1991.

Cuentas de Gonzalo de Baeza. Tesorero de Isabel la Católica, Ed. de A. de la Torre y E.A. de la Torre. Tomo II: 1492-1504. Madrid, 1956.

Díez del Corral, R., "El alcázar medieval”, en Checa, F. (Dir.), El Real Alcázar de Madrid. Dos siglos de arquitectura y coleccionismo en la corte de los Reyes de España, Madrid: Nerea, 1994a, pp. 133-134.

Díez del Corral, R., "El Alcázar de Carlos V", en Checa, F. (Dir.), El Real Alcázar de Madrid. Dos siglos de arquitectura y coleccionismo en la corte de los Reyes de España, Madrid: Nerea, 1994b, pp. 135-138.

Domínguez Casas, R., Arte y etiqueta de los Reyes Católicos. Artistas, residencias, jardines y bosques, Madrid, 1993.

Estella, M., "Encargo a Gregorio Vigarny de la portada principal del Antiguo Alcázar de Madrid", en Archivo Español de Arte, 1980, p. 124.

Fernández Álvarez, M., Carlos V, el César y el Hombre, Madrid, 1999.

Ferrandis, J., Datos documentales para la Historia del Arte español. Inventarios Reales (Juan II a Juana la Loca), Madrid, 1943.

Gerard, V., "Los sitios de devoción en el Alcázar de Madrid: capilla y oratorios”, en Archivo Español de Arte, n. ${ }^{\circ} 223,1983$, pp. 275-283.

Gerard, V., De Castillo a Palacio. El alcázar de Madrid en el siglo XVI, Madrid: Xarait, 1984.

Gerard, V., "L'escalier de l'Alcazar de Madrid", en L'escalier dans l'architecture de la Renaissance, París: Picard, 1985, pp. 161-164.

Gómez Martínez, J., “Alonso de Covarrubias, Luis de Vega y Juan Francés en el Alcázar real de Madrid (1536-1551)", en Academia, n. ${ }^{\circ}$ 74, 1992, pp. 200-232.

Herranz, J., "Dos nuevos dibujos del maestro real Gaspar de Vega: el primer plano del alcázar de Madrid, atribuido a Alonso de Covarrubias, y el plano de la Casa de Servicios del Palacio del Pardo", en Anuario de Historia y Teoría del arte, UAM, vols. IX-X, 1997-1998, pp.117-132.

Kagan, R.L., Ciudades del Siglo de Oro: las vistas españolas de Anton Van den Wyngaerde, Madrid. El Viso, 1986.

Arch. esp. arte, LXXXVII, 348, OCTUBRE-DICIEMBRE 2014, 335-350

ISSN: 0004-0428, eISSN: 1988-8511, doi: 10.3989/aearte.2014.21 
Ladero Quesada, M. Á.,“Los alcázares reales en la Baja Edad Media castellana: política y sociedad”, en Castillo Oreja, M. Á. (ed.), Los alcázares reales, Madrid, 2001, pp. 11-36.

Ladero Quesada, M. Á., "La receptoría y pagaduría general de la Hacienda regia castellana entre 1491 y 1494 (De Rabí Meír Melamed a Fernán Núñez Coronel)”, En la España Medieval, n. ${ }^{\circ}$ 25, 2002, pp. 425506.

León Pinelo, A., Anales de Madrid (desde el año 447 al de 1658), Madrid, 1971.

Libro de acuerdos del concejo madrileño. Tomo IV. 1498-1501, Edición de Carmen Rubio Pardos, Rosario Sánchez y Carmen Cayetano, Ayto. de Madrid, Archivo de Villa, 1982, p. 69.

Libro de acuerdos del concejo madrileño. Tomo V. 1502-1515, Ayto. de Madrid, Archivo de Villa, 1987.

Llaguno y Amirola, E., Noticias de los arquitectos y arquitectura de España desde su restauración, Madrid, 1829.

Lopezosa Aparicio, C., "Madrid: hacia la preparación de un escenario cortesano", en Anales, N. ${ }^{\circ}$ extraordinario, Vol. 23, 2013, pp. 159-169.

Marías, F., "La Casa Real Nueva de Carlos V en la Alhambra: letras, armas y arquitectura entre Roma y Granada", en Marías, F. y Pereda, F. (com.), Carlos V. Las armas y las letras. Sociedad Estatal para la conmemoración de los centenarios de Felipe II y Carlos V. Madrid, 2000, pp. 201-221.

Marías, F.; Gerard, V., "De Madrid à Paris: François Ier et la Casa de Campo", en Revue de l'Art, n 91, 1991, pp. 26-35.

Martín González, J. J., "El Alcázar de Madrid en el siglo XVI (nuevos datos)”, en Archivo Español de Arte, vol. XXXV, 1962, pp. 1-19.

Montero Vallejo, M., "El entorno del alcázar de Madrid durante la Baja Edad Media", en La ciudad hispánica, Ed. Universidad Complutense de Madrid, Madrid, 1985.

Morales Martínez, A.J. y Serrera Contreras, J.M., “Obras en los Reales Alcázares de Sevilla en tiempo de los Reyes Católicos", en Laboratorio de Arte, n. ${ }^{\circ}$ 12, 1999, pp. 69-77.

Rábade Obradó, M.P., "Escenario para una Corte real: Madrid en tiempos de Enrique IV”, en $e$-Spania, n. ${ }^{\circ}$ 8, 2009, Revista electrónica en http://e-spania.revues.org/18883 (consultada 14-X-2013).

Ruméu de Armas, A., Itinerario de los Reyes Católicos, Madrid, 1974.

Tormo, E., Las murallas y las torres, los portales y el alcázar del Madrid de la Reconquista, Madrid, Instituto Diego Velázquez, 1945

Ureña Uceda, A., La escalera imperial como elemento de poder. Sus orígenes y desarrollo en los territorios españoles en Italia durante los siglos XVI y XVII, Madrid, Fundación Universitaria Española, 2007.

Urgorri Casado, F., "El ensanche de la villa de Madrid en tiempos de Juan II y Enrique IV", en Revista de la Biblioteca, Archivo y Museo, 1, Ayto. de Madrid, 1954, pp.197-238.

Valdés Fernández, F., "El Madrid islámico. Notas para una discusión arqueológica", en Mayrit. Estudios de arqueología medieval madrileña, Madrid, Ed. Polifemo, 1992, pp. 152-154.

Wethey, H. E., "Escaleras del primer Renacimiento español", en Archivo Español de Arte, XXXVII, 148, 1964, pp.295-306.

Fecha de recepción: 20-XI-2013

Fecha de aceptación: 07-V-2014

Arch. esp. arte, LXXXVII, 348, OCTUBRE-DICIEMBRE 2014, 335-350 ISSN: 0004-0428, eISSN: 1988-8511, doi: 10.3989/aearte.2014.21 